\title{
Sustainable packaging as a tool for global sustainable development
}

\author{
Natalia Kozik ${ }^{1, *}$ \\ ${ }^{1}$ Cracow University of Economics, Department of Packaging Science, Poland
}

\begin{abstract}
In various areas of human activity more attention is paid to environmental and ecological problems and also social issues. International enterprises take into account these criteria in management and strive to reduce the degradative impact and negative effects of their activities. These activities include the global concepts of sustainable development, circular economy and social responsibility. These concepts are also increasingly taken into account by companies from the packaging industry. For this reason, more often we hear about the so-called "sustainable packaging", which is a consequence of the above actions and brings new opportunities in the environmental, economic, ethical and social aspects. The aim of the article was to characterize sustainable packaging. Based on the literature, sustainable packaging was defined, at the same time indicating that although this definition shows how to improve the packaging present on the global market, it should also be constantly improved and adapted to the changing market, society or environment requirements, as well as the state and development of the packaging industry. Examples of companies' around the world activities in the field of creating sustainable packaging were also presented.
\end{abstract}

\section{Introduction}

Society is constantly evolving and looking for new solutions, which has led, among others, to the great breakthrough that is globalization and economic development possible thanks to it. However, this is accompanied by unavoidable changes occurring both in the local and global environment, but they are not always positive. One example is environmental degradation, which has now become a global problem [1]. Also, one of the manifestations and effects of general globalization processes is consumerism. As a result, more and more attention is paid in various areas of human activity to social and environmental issues. Therefore, more and more often talk about eco-human globalization, and the subject of the impact of the economy on the environment and its users are taken in research carried out for the needs of science and economic practice. More and more enterprises include environmental and social criteria in management and strive to reduce the degradative impact and negative effects of their activities. These activities are determined by various administrative and legal instruments and solutions undertaken at the level of international economic policy, as well as the expectations and growing requirements of various

\footnotetext{
* Corresponding author: natalia.kozik@uek.krakow.pl
} 
stakeholder groups [2] of which consumers are the most important group. Currently, there are changes in their behavior. Increasingly, they perceive the relationship between their activities and the impact on the environment and society in general. They realize that shopping is not only an economic activity but it also causes some effects for other participants in the economy. There is a growing disappearance of egoistic motivations in favor of pro-social and pro-environmental behaviour. This is a consequence of, among others greater consumer awareness, which is the result of adequate society education, as well as the development of so-called IT society which can quickly convey opinions, e.g. about products, and create consumption trends [3, 4].

There is more and more talk about the so-called economics of sustainable development. This is a global trend that is somewhat the result of globalization. Unfortunately, pollution knows no geographical boundaries, and shrinking resources and the energy crisis affect all of humanity. On the other hand, without globalization, sustainable development would be significantly impeded, as it enables technical and technological progress as well as international cooperation at a global level, which contributes to balanced economic and social development. The main goal of sustainable development is to ensure appropriate ecological, economic and socio-cultural standards for current and future generations, taking into account the limits of nature's tolerance and realizing the principle of intra- and intergenerational justice [5]. The sustainable development paradigm assumes that this strategy should intensify economic growth taking into account justice, security and environmental quality as a social good. Achieving sustainable development goals is possible primarily through sustainable production and consumption. Actions taken in connection with its implementation should be constantly improved and have a dynamic and open nature. They should be adapted to the state of the economy and the changing needs of its participants, as well as the state of the environment. Concepts of the circular economy and social responsibility perfectly fit these priorities and without them, sustainable development would not be possible. They currently determine the development directions of many industries, which undoubtedly also includes packaging business [4, 6].

\section{Sustainable packaging}

Packaging are designed and manufactured to fulfill many functions important for its users consumers, and producers of packaged products. In globalization, the development of international corporations takes place, which is possible thanks to the free flow of goods and the opening of state borders and all of this favors the development of packaging. In addition to exports, the packaging market is fueled by the consumption and trends of the society and the development of other industries showing a need for packaging. Modern society cannot survive without packaging. The world's population is steadily increasing and supply chains are becoming increasingly complex. According to the Smithers Pira report entitled "The Future of Global Packaging to 2022" will see a 2.9\% increase in the value of global packaging market every year, and its reach USD 980 billion in 2022 [7]. Their main role is to prevent the loss of goods. Thanks to them, it is possible to provide the public with safe and quality products. They are also an excellent marketing tool with which entrepreneurs can influence the consumer.

Currently, environmental aspects have also gained importance in global packaging development trends. Unfortunately, after the packaging are used, they are waste that can have a significant impact on the environment. This applies especially to single-use packaging and to those made of various packaging materials. For this reason, certain legal regulations have been introduced which are aimed at creating a pro-environmental and prosocial industry from the packaging business. In addition, activities in this field are conditioned by the impact of globalization and the economic situation on the global 
economy, technical and technological progress as well as the growing needs and requirements of society. For this reason, they are used to improve the market position of enterprises and create the image of ethically operating companies and with respect for the natural environment and its users. This is the reason for the adaptation of production to the implementation of the principles of the above concepts and recognizing them as an integral part of the enterprise management strategy by companies from the packaging industry, which belongs to the dynamically developing economic sectors and packaging design, which throughout their life cycle will be in line with the assumptions of sustainable development $[8,9]$, and meet the expectations and needs of users.

The concept of "sustainable packaging" is increasingly used in international literature. This is difficult to define due to the multitude of criteria which should be considered, a large variety of packaging materials, as well as the dynamic development of the industry. Theoretically, these are packaging that, compared to conventional packaging, meet higher environmental, economic and social standards, have better performance and quality features, and at the same time bring new possibilities in the field of the recovery and waste management. These standards should apply to the entire packaging life cycle - from production, through packaging, distribution, transport processes, to use and disposal [9].

Researchers trying to describe sustainable packaging usually refer to definitions developed by non-profit organizations. One of them is the American organization Sustainable Packaging Coalition. SPC considers sustainable packaging as packaging that $[10,11,12]$ :

- throughout the entire life cycle is beneficial, safe and healthy for individuals and society as a whole,

- meets market criteria for efficiency and costs,

- is obtained, produced, transported and recycled using renewable energy,

- optimizes the use of renewable or recycled source materials,

- it is produced using cleaner production technologies and best practices,

- it is made of materials that are safe for health under all foreseeable conditions of usage throughout its life cycle,

- it is designed to optimize materials and energy,

- it is designed in the way to optimize materials and energy usage,

- is effectively recovered and used in biological and / or industrial closed circuits, i.e. from cradle to cradle.

In turn, the definition of another institution, i.e. the Australian Sustainable Packaging Alliance, includes how important role plays packaging in global social and economic systems and the need to gain environmental goals. The efficiency of the packaging throughout its life cycle, the impact of the environmental performance of materials (impact and waste prevention) on society and the environment, and the ecological toxicity of the packaging components and their interaction with the product were also taken into account. According to SPA, packaging should be $[9,13,14]$ :

- effective - should add economic and social value to the product,

- efficient - should minimize the use of materials and energy,

- cyclical - should optimize the recovery of materials and minimize their degradation,

- safe - should not pose a threat to the life and health of users and to ecosystems.

Another organization dealing with the topic of product packaging and environmental protection - the European Organization for Packaging and Environment does not use the concept of "sustainable packaging". However, it encourages packaging design that contributes to sustainable development. According to EUROPEN, this packaging should [14]:

- be holistically designed with the product to optimize overall environmental performance,

- be made of responsibly obtained materials, 
- be designed to be effective and safe throughout the life cycle in order to protect the product,

- meet market criteria for efficiency and costs,

- meet the expectations and needs of consumers,

- be effectively recycled or recovered after use.

EUROPEN's work in this area recognizes the major contribution to the global sustainable production and consumption of packaging, helping to reduce product waste and conserving resources while recognizing that packaging consumes resources at all stages of the supply chain [14].

When formulating one definition, one can use analogies appearing in the definitions developed by the abovementioned organizations. As it results from the above, all these definitions - despite being developed by organizations operating in different geographical areas - consider packaging in 5 basic areas that are the pillars of sustainable packaging, i.e. (Fig. 1.):

- environment (e.g. reducing the negative impact of packaging on the environment throughout its life cycle),

- society (e.g. meeting users' needs),

- economy (e.g. reduction of production, distribution and disposal costs),

- time (e.g. considering the impact of packaging on the future of the environment and next generations),

- development (e.g. supporting the development and increasing the innovativeness of enterprises),

and emphasize that sustainable packaging should perform all its functions at least to a satisfactory degree.

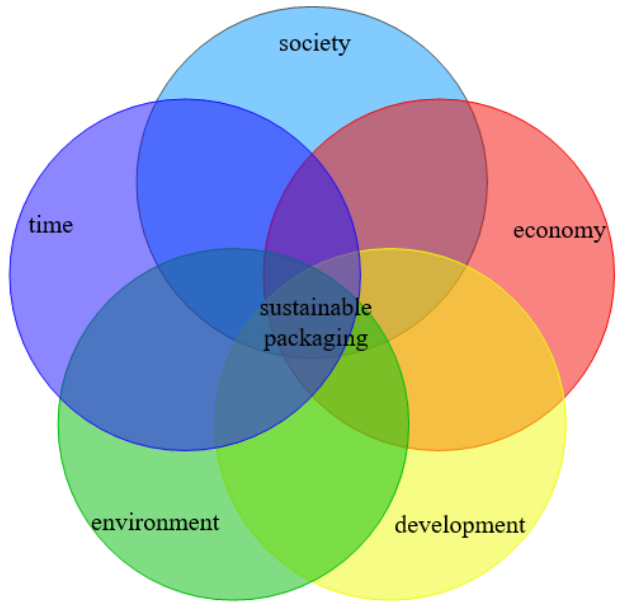

Fig. 1. Sustainable packaging.

The above definitions show how to improve the packaging present on the market, but they should also be constantly improved and adapted to the changing requirements of the market, society or the environment, as well as to the state and development of the packaging industry. Achieving saturation, in this case, is not possible and packaging improvement is undoubtedly a process of continuous, dynamic changes and the search for new solutions. Technologies and innovations developed in this area support smart growth, the use of, for example, recovered resources supports sustainable growth, and taking into account the needs of society supports inclusive growth. As can be seen from the above, the packaging industry is taking action in all three priority areas of sustainable development, and packaging are ones of its important tools. Increasingly, they are produced in accordance 
with its principles and are the optimal solution for the environment, thus bringing benefits to society, while generating profits for the company. At the same time, they are its consequence, but also a factor driving further changes due to the size of the industry and the important role of these products.

\section{Examples of sustainable packaging}

Manufacturers wanting to adapt the industry to the current requirements and changes are looking for new solutions by creating innovative biodegradable packaging materials or using renewable raw materials. However, packaging made of conventional materials such as plastics, paper, glass, and metal can also meet the requirements of sustainable packaging. It is often enough to analyze their life cycle and improve certain areas related to their production, use or disposal, which can sometimes be time and labor-intensive, but not impossible. The following are examples of packaging from conventional materials that can be described as sustainable. They were listed as sustainable packaging in "Design for Recycled Content Guide" developed by SPC [12].

In the production of packaging, plastics are one of the most widely used materials on a global scale, mainly due to their versatility. They are mainly used for packaging food and beverages, cosmetics, pharmaceutical, and industrial products. Contrary to popular opinion, they are particularly suitable for the production of sustainable packaging - they provide protection, are durable, and thanks to the low weight of the packaging, they reduce the cost of transport and associated greenhouse gas emissions. In addition, they can be easily formed into any shape [15]. Unfortunately, they are often not managed properly after use and this is a global problem. Plastic products is the most common marine waste, which in terms of quantity is $80-85 \%$ [16]. Mostly they are packaging i.a. bottles made of PET. For this reason, organizations and producers are looking for new methods of recovery and the use of plastics obtained in this way. An example would be the solution proposed by the Canadian company Loop ${ }^{\mathrm{TM}}$ Industries. This company has developed a technology for the recovery of all waste made of PET, which allows obtaining high-purity plastic. The process involves depolymerization of PET waste resulting in dimethyl terephthalate (DMT) and monoethylene glycol (MEG). This process consumes no energy. Then the so-called Loop ${ }^{\mathrm{TM}}$ PET is formed. This material is made from $100 \%$ recycled content. In addition, it can be reused in the food industry because it is of high quality and meets the FDA requirements for materials intended for contact with food. One of the companies that concluded an agreement with Loop ${ }^{\mathrm{TM}}$ Industries in 2019 is Danone SA, one of the largest global producers in the food and drink sector. Loop ${ }^{\mathrm{TM}}$ PET is to be used for the production of packaging, i.a. the iconic evian ${ }^{\circledR}$ water, but also the company's other brands. The result will be the market launch of water bottles made of $100 \%$ PRC (post-consumer recyclate) by 2025. In addition to Danone, other global manufacturers and retailers such as CocaCola, PepsiCo, L'OCCITANE Provence, and L'Oreal decided to cooperate with Loop Industries $[12,17]$.

In addition to plastics, paper products are widely used in the production of packaging around the world. They are used for the production of wrappings, labels, unit packaging and, above all, for transport packaging. They are valued primarily for their biodegradability. Unfortunately, in this process greenhouse gas, which is methane, is produced [18]. Therefore, these packaging should be recycled, which will reduce methane emissions as well as the quantity of packaging waste. According to United States Environmental Protection Agency, recycling 1 ton of this material allows a reduction of greenhouse gases by 1 metric ton of carbon equivalent (MTCE) [19]. It would also save 7,000 gallons of water and enough energy to power the average American home for six months. Unfortunately, recycled paper is rarely used in the production of packaging 
intended for contact with food due to the impurities present in the material, which negatively affect its hygienic properties and aesthetics. In addition, it is often coated, for example, with plastics, what take place in the production of disposable cups and because of that, their recycling is a challenge [20]. However, Starbucks, which has its cafes around the world, has committed to doubling recycled paper in their cups by 2022 (they are now made from recycled material in 10\%) and also recycling used cups. In the project called Cup to Cup: Closing the Loop, cooperation with supply chains partners such as Sustana, Seda and WestRock was announced. The goal of the project is to develop a system in which used cups will be sent to Sustana, where cups will be converted into pulp. Then the raw material thus obtained is sent to WestRock, where a paper product is created. After this, the material goes to Seda, where cups made of $100 \%$ recycled paper are made [12, 21].

Glass is another raw material used in the production of packaging. It is most often used to make packaging for beverages, alcohol or pharmaceutical products [Emblem]. These packaging are valued primarily for aesthetic appearance and chemical safety. However, the process of their production is highly energy-consuming, which generates costs, and also promotes the formation of greenhouse gases, and the glass is not biodegradable. As an example of sustainable glass packaging, can be given a bottle of the global brand Absolut Vodka. This company uses over 1 million bottles annually, which use $40 \%$ of recycled raw materials. This allows you to reduce energy consumption by $10 \%$. The number of greenhouse gases is also reduced - for every 6 tons of cullet 1 ton less $\mathrm{CO}_{2}$, and every $10 \%$ of cullet in the product reduces the amount of solid particles by $8 \%$, nitric oxide by $4 \%$ and sulfur oxide by $10 \%$. In addition, the company produces bottles at a local glass factory in Limmared, near its headquarters in Ahus, Sweden, which allows minimizing the negative effects of transport [12, 22].

Another conventional packaging material is metal, namely steel and aluminum. They are commonly used for the production of cans, caps, closures and foils. Aluminum is a chemically inert material, resistant to corrosion and low and high temperatures. For this reason, aluminum foil is readily used in households. Although aluminum is the most common metal in the earth's crust, its processing is a complex process because it does not exist in its pure form. It is extracted and smelted from bauxite ore at high temperatures [23]. However, this is one of the most commonly recovered packaging materials but this does not apply to foils made of this material. The solution that eliminates these drawbacks is, for example, Aluminum foil manufactured by Reynolds Kitchen. This company offers a product made of $100 \%$ recycled raw material - a mixture of aluminum processed from post-industrial and post-consumer waste. This material is completely safe for food and can be recycled again. An additional advantage is the lower raw material consumption of the entire process - producing aluminum from recycling requires $95 \%$ less energy, because it does not need to be extracted and remelted. In addition, greenhouse gas emissions are $95 \%$ lower than during primary aluminum production. In addition, the production of the foil itself is also less energy-intensive - by $80 \%[12,24]$.

The presented solutions meet all the features of sustainable packaging. First of all, they are environmentally friendly. To a large extent, they use recyclable materials, seek to optimize resource consumption, and take into account the product life cycle from cradle to cradle, which reduces the negative environmental effects. In addition, these packaging are intended for the packaging of consumer goods, and therefore will be easily accessible to consumers and will meet their needs and expectations. They have standard construction forms and are made of traditional materials so there is a high probability that they will be well received by potential buyers. They also meet legal requirements in the field of security. As it results from the above, they will not only meet the needs of current generations, but also will not limit the possibilities of future generations in this respect. In addition, these solutions will not generate additional costs, because technologies are 
economically profitable. They support the development of companies that strive to search for new opportunities in this area, constantly adapting these products to the changing needs of consumers, the environment and market practice. Activities in the packaging sector are one of the priority areas enabling adjustment of companies' activities to sustainable development. Enterprises make efforts in this area knowing that they can contribute to achieving the objectives set out in their policies, which are conditioned by the broadly understood needs of society and increasingly by legislation at national and international level. Such packaging are undoubtedly a tool supporting the concept of sustainable development.

\section{Conclusion}

Progressing and broadly understood globalization carries many threats, but also positive aspects. This also applies to the packaging industry, which is undergoing constant and dynamic changes. Globalization and related trends are one of the factors shaping business dynamics and determining the development of the packaging industry.

Due to the free flow of goods and their large diversification, packaging plays a key role in today's competitive economy in almost every industry, its sectors and supply chains. For this reason, it is important to design packaging that throughout the entire life cycle will be in line with the concepts that guide the development of the industry, i.e. sustainable development, the circular economy and corporate social responsibility.

More and more companies are taking steps to create a pro-environment and pro-social industry from the packaging industry. They consider packaging not only in economic terms but also environmental, social and ethical. They are constantly looking for new solutions aimed at improving packaging present on the market and adapting them to the state and changing requirements of the market, society or the environment. Innovative materials are also of great importance, but also technologies that allow adaptation of conventional materials to transformations and new applicable standards. Sustainable packaging is the result of a process approach in which certain attributes are added to a standard product that increase the economic, social and environmental value throughout its entire life cycle. These 3 pillars: economic development, social development and environmental protection are the basis of sustainable development, whose integral area is packaging. Achieving saturation is not possible in this case, and balanced packaging is also a consequence and stimulus of sustainable development.

\section{References}

1. A. Schaffartzik, J. Antonio Duro, F. Krausmann, Global appropriation of resources causes high international material inequality - Growth is not the solution, Ecological Economics, 163, 9-19 (2019)

2. C. Sassanelli, P. Rosa, R. Rocca et al., Circular economy performance assessment methods: A systematic literature review, Sustainability 229, 440-453 (2019)

3. N. Perra, L. E. C. Rocha, Modelling opinion dynamics in the age of algorithmic personalisation, Scientifics Reports 9, article number: 7261 (2019)

4. G. Orzan, A. F. Cruceru, C. T. Bălăceanu, R.-G. Chivu, Consumers' Behaviour Concerning Sustainable Packaging: An Exploratory Study on Romanian Consumers, Sustainability 10, 1-11 (2018)

5. A. Krysovatyy, A. Mokiy, R. Zvarych et al., Alterglobalization via the inclusive circular economy paradigm, Economic Annals - XXI 174, 4-9 (2019) 
6. A. Androniceanu, Social responsibility, an essential strategic option for a sustainable development in the field of bio-economy, Amiteatru Economic 21, 503-519 (2019)

7. Smithers Pira, The Future of Global Packaging to 2022 (2017)

8. Ma X., Moultrie J., What stops designers from designing sustainable packaging? - a review of eco-design tools with regard to packaging design, Smart Innovation Systems and Technologies 68, 127-139 (2017)

9. H. Żakowska, Opakowania a środowisko. Wymagania, standardy, projektowanie, znakowanie (Wydawnictwo PWN, Warszawa, 2017)

10. Jr. J. U. Gustavo, G. M. Pereira, A. J. Bond, C. V. Viegas, M. Borchardt, Drivers, opportunities and barriers for a retailer in the pursuit of more sustainable packaging redesign, Journal of Cleaner Production 187, 18-28 (2018)

11. Sustainable Packaging Coalition, Definition of Sustainable Packaging [online], https://sustainablepackaging.org/wp-content/uploads/2017/09/Definition-ofSustainable-Packaging.pdf (2011)

12. Sustainable Packaging Coalition, Design for Recycled Content Guide (2019)

13. M. Strzałkowski, Gospodarka o obiegu zamkniętym: nowy plan dla Europy. Raport specjalny 2018, Jak madrze zaprojektować gospodarke?? [online], https://euractiv.eu/wp-content/uploads/sites/6/special-report/EA-SPECIAL-REPORTEURACTIV-PL-V01.pdf (2018)

14. EUROPEN, Green Paper. Packaging and sustainability. An open dialogue between stakeholders [online], https://europen-packaging.eu/sustainability/packagingenvironment.html (2011)

15. A. Sangroniz, J.-B. Zhu, X. Tang et al., Packaging materials with desired mechanical and barrier properties and full chemical recyclability, Nature Communications 10, article number: 3559 (2019)

16. Directive (EU) 2019/904 of the European Parliament and of the council of 5 June 2019 on the reduction of the impact of certain plastic products on the environment

17. https://www.loopindustries.com

18. L. S. Dislikes-Hoffman, J. L. Lane, T. Grant et al., Environmental impact of biodegradable food packaging when considering food waste, Journal of Cleaner Productio 180, 325-334 (2018)

19. https://archive.epa.gov/wastes/conserve/materials/paper/web/html/index-2.html

20. V. B. Rastogi, P. Samyn, Bio-Base Coatings for Paper Applications, Coatings 5(4), 887-930 (2015)

21. https://www.sustanagroup.com/newsroom/cup-cup-closing-loop-partnership-projectstarbucks/

22. https://www.ardaghgroup.com/news-centre/the-absolut-company-and-ardagh-groupsign-10-year-partnership

23. A. Emblem, H. Emblem, Packaging technology: fundamentals, materials and processes (Woodhead Publishing Ltd, Cambridge, 2014)

24. https://www.reynoldskitchens.com/products/aluminum-foil/recycled/ 